\title{
HUBUNGAN PEMBERIAN SUSU FORMULA MENGGUNAKAN BOTOL DENGAN RAMPAN KARIES PADA ANAK (STUDI LITERATUR)
}

\author{
Nurwiyana Abdullah, Munadirah
}

\begin{abstract}
ABSTRAK
Susu formula bayi adalah cairan atau bubuk dengan formula tertentu yang diberikan pada bayi dan anak-anak, berfungsi sebagai pengganti ASI. Ada beberapa penyebab yang mempengaruhi kerusakan gigi pada anak, diantaranya penggunaan susu botol, banyak orang tua yang mengeluh banyak gigi anak kecoklatan, mahkota gigi yang rusak, bahkan terkadang sudah tinggal sedikit saja mahkota yang tersisa namun banyak para ibu yang tidak menyadari apa penyebab yang sesungguhnya terjadi pada gigi anaknya tersebut yaitu mengalami karies botol (rampan karies). Tujuan penelitian ini adalah untuk mengetahui hubungan minum susu formula menggunakan botol dengan rampan karies pada anak. Metode penelitian yang digunakan adalah kepustakaan/library research yaitu pengumpulan data yang berasal dari sumber data sekunder seperti jurnal, buku, karya tulis ilmiah, skripsi dan text book yang telah melakukan penelitian tentang hubungan pemberian susu formul menggunakan botol dengan rampan karies pada anak. Ada 6 hasil penelitian yang digunakan dan memiliki kesinkronan dari judul studi pustaka ini. Hasil studi pustaka menunjukkan bahwa terdapat hubungan pemberian susu formula menggunakan botol dengan rampan karies pada anak.
\end{abstract}

Kata kunci: Susu formula, Karies Botol, Rampan karies.

\section{PENDAHULUAN}

Kesehatan gigi dan mulut bagian dari kesehatan badan, ikut berperan dalam menentukan status kesehatan seseorang.Untuk menilai status kesehatan gigi dapat dilihat dari ada dan tidaknya penyakit gigi, di antaranya karies gigi. Karies gigi merupakan penyakit gigi yang paling banyak di temukan, meliputi semua usia dan lapisanmasyarakat yang jika tidak diketahui sejak dini dan di biarkan berlanjutan dapat menjadi lebih parah. Selain itu timbul pula komplikasi yang serius berupa penyakit ginjal, jantung, saraf dan sebagainya (Zahara, 2018).

Berdasarkan Kementerian Kesehatan pada tahun 2013 Provinsi yang mempunyai masalah gigi dan mulut yang cukup tinggi (>35\%) adalah Provinsi Sulawesi selatan, Kalimantan Selatan, dan Sulawesi Tengah dengan masing-masing EMD 10,3\%, 8\% dan 6,4\%. Bila dibandingkan tahun2007 dan 2013 peningkatan masalah gigi dan mulut tertinggi adalah Provinsi Sulawesi Selatan (10,9\%), DI Yogyakarta (8,5\%) dan Jawa Timur (8,3\%). Sedangkan Provinsi Jambi, Riau, Bengkulu, mengalami penurunan masalah gigi dan mulut masing-masing 8,3\%, 6,\%, dan 6,3\% (Kemenkes,2014).

Ada beberapa penyebab yang mempengaruhi kerusakan gigi pada anak, diantaranya penggunaan susu botol, banyak orang tua yang mengeluh banyak gigi anak kecoklatan, mahkota gigi yang rusak, bahkan terkadang sudah tinggal sedikit saja mahkota yang tersisa namun banyak para ibu yang tidak menyadari apa penyebab yang sesungguhnya terjadi pada gigi anaknya tersebut yaitu mengalami karies botol (rampan karies) (Zahara, 2018).

Kejadian rampan karies tersebut dapat dicegah lebih awal melalui pemahaman dan peran serta orang tua terutama ibu dalam memelihara kerusakan gigi anak. Kebanyakan kaum ibu tidak mengetahui bahwa susu botol atau cairan yang manis dapat melekat pada permukaan gigi bila tidak dibersihkan.

Dengan ini peneliti beralasan untuk melakukan penelitian dikarenakan masih banyak disekitarnya anak umur pra sekolah yang mengonsumsi susu formula menggunakan botol 
maupun tidak menggunakan botol yang mempunyai masalah pada gigi sulung yang biasa disebut rampan karies, banyaknya orang tua khususnya para lbu yang memberikan anaknya susu formula bukan ASI dikarena banyak faktor seperti adanya pekerjaan, serta pemberian susu formula dianggap hal praktis dan mudah bagi para Ibu, belum adanya kebiasaan anak untuk minum susu menggunakan gelas, dan ketidak tahuan para lbu akan efek minum susu menggunakan botol.

Pada penelitian sebelumnya yang dilakukan oleh Andriani Elfi Zahara (2018) adalah “ Hubungan Pemberian Susu Menggunakan Botol Dengan Rampan Karies Pada Murid Tk Hj. Cut Nyak Awan Gampong Lambaro Kec. Ingin Jaya Kab. Aceh Besar" dengan hasil penelitian ada hubungan antara cara pemberian susu mengunakan botol dengan rampan karies $(p=0,000)$.

\section{METODE PENELITIAN}

Penelitian ini menggunakan pendekatan deskriptif kualitatif, dan jenis penelitian yang digunakan adalah studi literatur yaitu mengumpulkan data dalam buku, jurnal, text book, skripsi, karya tulis ilmiah, majalah maupun koran yang bertujuan dengan obyek penelitian dan pengumpulan data yang bersifat kepustakaan atau yang telah dilaksanakan untuk memecahkan suatu masalah yang pada dasarnya tertumpu pada penelaahan kritis dan mendalam terhadap bahan-bahan pustaka yang relevan. Penelitian ini termasuk penelitian study literatur. Oleh karena itu teknik yang digunakan dalam pengumpulan data adalah pengumpulan bahan-bahan pustaka yang koheren dengan objek pembahasan yang dimaksud. Data yang ada dalam kepustakaan tersebut dikumpulkan dan diolah. Analisis data dalam kajian pustaka (Library Research) ini adalah Analisisi (content analysis) yaitu penelitian yang bersifat pembahasan mendalam terhadap isi suatu informasi tertulis atau tercetak dalam bentuk buku, jurnal, textbook, dst.

\section{HASIL DAN PEMBAHASAN}

Susu formula adalah susu yang sering diberikan pada bayi sebagai pengganti ASI (Air Susu Ibu) yang cara pemberiannya biasa menggunakan botol. ASI sering digantikan dengan susu formula dikarenakan beberapa faktor penyebab yang biasa terjadi dikalangan masyarakat, antara lain ASI sejak pertama kelahiran belum lancar sehingga penggunakan susu formula menggunakan botol menjadi salah satu anjuran, kesibukan lbu juga karena pekerjaan merupakan salah satu alasan pemberian susu formula menggunakan botol, dan pemberian susu formula menggunakan botol dianggap praktis sehingga susu formula menggunakan botol sangat diminati oleh para Ibu.

Pemberian susu formula menggunakan botol merupakan salah satu penyebab dari adanya rampan karies pada anak, biasa dikarenankan cara pemberian susu formula menggunakan botolnya salah, dan juga lama pemberian susu formula menggunakan botol merupakan salah satu penyebab rampan karies.

Menurut Rr. Bamandhita Rahma Setiaji (2019) karies rampan adalah masalah perlubangan gigi yang terjadi sangat cepat dan tiba-tiba, serta menyebar luas sehingga langsung mengenai pulpa (bagian tengah gigi), Pada karies rampan, gigi berlubang lebih disebabkan oleh sisa-sisa makanan yang menumpuk jadi plak pada gigi anak, Karies rampan lebih sering terjadi pada anak-anak usia di bawah lima tahun. Paling banyak ditemukan pada anak usia empat tahun. Orang dewasa juga bisa kena karies rampan. Karies rampan ini terjadi pada gigi susu, bisa salah satu saja atau beberapa gigi sekaligus; termasuk gigi yang seharusnya kebal terhadap karies, seperti gigi seri depan bawah, Karies dikatakan rampan (rampant) karena bisa 
menyerang sampai 10 gigi dalam satu waktu Pada penelitian sebelumnya terdapat beberapa hasil penelitian yaitu sebagai berikut:

Pada penelitian Aprilia Lombo, dkk tahun 2015 dengan judul "Status karies anak usia prasekolah sekolah Citra Kasih yang mengonsumsi susu formula". Dengan hasil penelitian berdasarkan pola konsumsi susu formula diperoleh hasil bahwa indeks def-t ratarata terendah berada pada kelompok anak yang mengonsumsi susu formula lebih dari dua tahun, lebih dari tiga kali sehari, lebih dari 15 menit, tanpa penambahan gula, dan disertai pemberian air putih.

Berdasarkan hasil di atas, terlihat bahwa pola konsumsi susu formula yang dipaparkan merupakan pola konsumsi yang kurang tepat, namun memiliki hasil indeks def-t rata-rata terendah. Hal ini disebabkan karena cara penyajian susu formula yang mayoritasnya tidak diberi tambahan pemanis, sehingga memengaruhi status karies anak. Penambahan pemanis pada penyajian susu formula dapat berpotensi menyebabkan karies. Cairan susu formula yang telah diberi tambahan pemanis ini akan melekat cukup lama pada permukaan gigi sehingga dapat menjadi media pertumbuhan bakteri karena adanya kandungan sukrosa. Selain itu, kandungan laktosa yang terdapat di dalam susu mengakibatkan demineralisasi email semakin cepat sehingga dapat berlanjut menjadi karies.

Perbedaan yang terdapat pada penelitian ini sesuai dengan hasil di atas bukan hanya disebabkan oleh perilaku orang tua dalam cara penyajian susu formula yang tidak disertai tambahan pemanis, namun hal ini disebabkan juga oleh faktor lain seperti pendidikan, pekerjaan, dan faktor sosial ekonomi orang tua yang turut berpengaruh terhadap status kesehatan gigi dan mulut anak. Anak-anak yang bersekolah di Sekolah Citra Kasih Manado, pada umumnya mempunyai orang tua dengan status pendidikan, pekerjaan, dan sosial ekonomi yang tergolong menengah ke atas sehingga mempunyai pengetahuan yang baik dalam membiasakan anaknya untuk menjaga kebersihan gigi dan mulut sejak dini sehingga anak dapat terhindar dari resiko besar terjadinya karies terutama dalam hal mengonsumsi susu formula. Dan hasil penelitian ini Status karies anak usia prasekolah Sekolah Citra Kasih Manado yang mengonsumsi susu formula tergolong dalam kategori rendah.

Berbeda dengan penelitian Rahmawati tahun 2016 dengan judul "Pengaruh Penggunaan Susu Botol Terhadap Terjadinya Rampan Karies Pada Anak TK Al. Bahra Kampung Beru Desa Bululoe Kabupaten Jeneponto.Dengan hasil penelitian didapatkan bahwa lebih besar responden yang menggunakan susu botol terkena rampan karies lebih tinggi dibandingkan dengan responden yang menggunakan susu botol tidak terjadi rampan karies, sedangkan responden yang tidak menggunakan susu botol dan tidak terjadi rampan karies lebih rendah daripada responden yang menggunakan susu botol yang angka kejadian rampan kariesnya tinggi. Jadi hasil uji square SPSS diperoleh nilai person Chi-Square sebesar 0,001, artinya tingkat signifikan uji lebih kecil dari $(0,05)$ sehingga terdapat pengaruh yang signifikan antara pemberian susu botol dengan kejadian rampan karies, Penelitian ini sependapat dengan penelitian pada tahun berikutnya yang diteliti Ghaitsa dkk tahun 2017 dan Endah Purwani Sari tahun 2017.

Pada penelitian Ghaitsa,dkk tahun 2017 dengan judul penelitian "Perbandingan Indeks Karies Antara Anak Yang Mengkonsumsi Susu Botol". Dengan hasil penelitian menyatakan bahwa anak yang mengkonsumsi susu menggunakan botol tingkat keparahan terkena karies gigi lebih tinggi dibanding anak yang mengkonsumsi susu tanpa botol. Hasil penelitian menunjukkan bahwa anak-anak yang mengkonsumsi susu tanpa botol tingkat 
kerusakan gigi lebih rendah dibanding anak yang mengkonsumsi susu menggunakan botol. Decay (gigi yang rusak karena karies) dan indicated forextraction (indikasi untuk dicabut/jumlah gigi sulung yang telah atau harus dicabut karena karies) lebih tinggi pada anak yang mengkonumsi susu botol dibandingkan anak yang mengkonsumsi susu tanpa botol, sedangkan filled (gigi yang telah ditambal karena karies) lebih banyak pada anak yang mengkonsumsi susu tanpa botol. Dapat disimpulkan bahwa indeks karies anak yang mengkonsumsi susu botol lebih tinggi dibanding tanpa botol. Indeks karies pada anak yang mengkonsumsi susu botol sebesar 5,3 yang termasuk dalam kategori tinggi. Indeks karies anak yang mengkonsumsi susu tanpa botol sebesar 3,4 termasuk dalam kategori sedang.

Pada tahun yang sama ada juga penelitian dari Endah Purwani Sari tahun 2017 yang berjudul "Hubungan pemberian susu formula dengan karies gigi pada anak pra sekolah di Tk Daniyyah Kids" dengan hasil penelitian menunjukkan bahwa anak yang diberikan susu formula yang mengalami karies gigi lebih tinggi dibandingka dengan yang diberikan susu formula namun tidak mengalami karies gigi. Dan yang tidak diberikan susu formula namun mengalami karies gigi berjumlah lebih rendah dibandingka dengan yang tidak diberikan susu formula namun tidak mengalami karies gigi. Dengan demikian dapat disimpulkan bahwa di TK Daniyyah Kids lebih banyak anak yang yang diberikan susu formula hasill uji statistic menunjukkan nilai pearson Chi-Square didapatan jika $\mathrm{p}$ Value $\leq$ 0,05 berarti Ho ditolak dan dari tabel 4.3 menunjukan bahwa nilai p Value 0,003 berarti Ho ditolak artinya ada hubungan yang signifikan antara pemberian susu formula dengan karies gigi.

Pada penelitian Andriani Elfi Zahara tahun 2018, dengan judul penelitian "Hubungan Pemberian Susu Menggunakan Botol Dengan
Rampan Karies Pada Murid TK HJ. Nyak Awan Gampong Lambaro Kec. Ingin Jaya Kab. Aceh Besar" telah didapatkan dari hasil penelitian Adriani Elfi Zahara yaitu Cara pemberian susu menggunakan botol kurang baik ada rampan karies lebih tinggi dibandingkan dengan cara pemberian susu menggunakan botol kurang baik tidak ada rampan karies. Serta cara pemberian susu menggunakan botol dengan baik ada rampan karies lebih rendah sedangkan cara pemberian susu menggunakan botol dengan baik tiadak ada rampan karies lebuh tinggi. Menurut pendapat peneliti masih minimnya pengetahuan orang tua tentang cara pemberian susu yang baik dan cara pencegahan karies sehingga pada saat memberikan susu menggunakan botol, anakanak tidak dilakukan pembilasan, berkumurkumur dengan air putih ataupun menggosok gigi. Jadi hasil penelitian yaitu hasil uji statistik menunjukkan ada hubungan cara pemberian susu menggunakana botol dengan rampan karies $(P=0,000)$.

Penelitian diatas sependapat dengan penelitian Lucia Yauri dan Renny Tungga Pratiwi Said tahun 2018 dengan judul "Hubungan Lamanya Pemberian Susu Formula Dengan Tingkat Keparahan Karies Gigi Pada Anak Usia 2-6 Tahun Di Tk Islam Sudiang Asri Kel. Pai Kec. Biringkanaya Kota Makassar". Dengan hasil penelitian uji statistik chi-square dan diperoleh $p$ value sebesar 0,0006, yang artinya terdapat hubungan yang signifikan antara lama pemberian susu formula dengan tingkat keparahan karies. Hal ini juga didukung oleh data yang menunjukkan bahwa sebagian besar sampel yang memberikan susu formula kepada anaknya terjadi rampan karies kepada anaknya dan penelitian ini sependapat dengan penelitian yang dilakukan oleh Dewi Sartika tahun 2012.

Dengan adanya beberapa penelitian diatas peneliti berasumsi bahwa dengan adanya beberapa hasil penelitian yang hampir sama yang dapat menunjang dengan judul penelitian 
studi literature ini yang berjudul hubungan pemberian susu formula menggunakan botol dengan rampan karies pada anak maka, peneliti menyimpulkan bahwa ada hubungan pemberian susu formula menggunakan botol dengan rampan karies pada anak. Tingginya angka rampan karies dapat dipengaruhi oleh cara pemberian susu formula yang kurang baik sehingga mengakibatkan tingginya angka anak yang mederita rampan karies.Tingginya angka penderita rampan karies pada anak dipengaruhi juga dengan banyaknya pemberian susu formula yang menggunakan botol, dan lamanya pemberian susu formula merupakan salah satu penyebab terjadinya rampan karies pada anak.

Ada beberapa keterbatasan yang didapatkan peneliti selama proses penyusunan diantaranya adalah keterbatasan referensi dari jurnal-jurnal penelitian sebelumnya yang lebih banyak meneliti tentang pengaruh dan gambaran pemberian susu botol dengan karies gigi.

Keterbatasan lain yang didapatkan peneliti adalah keterbatasan pengalaman penelitian. Hal ini sangat mempengaruhi peneliti dalam merumuskan hasil penelitian, dimana baru pertama kali diberlakukannya studi literature dalam penyusunan skripi ini. Selanjutnya keterbatasan akses internet di wilayah peneliti. Keterbatasan terakhir adalah keterbatasan sarana, situasi dan waktu dimana diketahui bersama bahwa pandemic Covid-19 menjadi salah satu masalah bersama saat ini kita alami

\section{KESIMPULAN DAN SARAN}

\section{Kesimpulan}

Dari hasil dan pembahasan dari beberapa penelitian yang sudah dikaji didapatkan kesimpulan bahwa anak yang minum susu formula menggunakan botol lebih tinggi angka terkena rampan kariesnya daripada anak yang minum susu formula tanpa botol. Dan dengan adanya beberapa hasil penelitian diatas yang mendukung judul penelitian study literatur ini maka dapat disimpulkan bahwa terdapat hubungan pemberian susu formula menggunakan botol dengan rampan karies pada anak.

Saran

Berdasarkan hasil studi literatur, maka disarankan agar orang tua terutama ibu hendaknya lebih memperhatikan kesehatan gigi anaknya dengan cara memperhatikan cara pemberian susu formula pada anaknya, agar tidak terdampak penyakit gigi dan mulut terutama rampan karies.

\section{DAFTAR PUSTAKA}

Achmad, M.H. 2016. Buku saku karies dan perawatan pulpa pada gigi anak. Jakarta: Sagungseto

Elfi Zahara, Adriani (2018). Hubungan pemberian susu mengunakan botol dengan rampan karies pada murid Tk Hj. Cut Nyak Awan Gampong Lambaro kecamatan Ingin jaya kabupaten Aceh besar. Jurnal averrous, vol.2, No.1,2018. Jurusan keperawatan gigi poltekkes kemenkes Aceh.

Ghaitsa, dkk. 2017. Perbandingan indeks karies antara anak yang mengkonsumsi susu botol dengan tanpa botol usia 2-5 tahun. Dentino (jur. Ked. Gigi), vol.II, no 2, September 2017, hlm 205-210. Program Studi Kedokteran Gigi Fakultas Kedokteran Gigi, Universitas Lambung Mangkurat, Banjarmasin.

Houwink, B, dkk. (1993).Ilmu kedokteran gigi pencegahan .Yogyakarta: Gadjahmada university press.

Kemenkes. "Info datin pusat data dan informasi kementerian kesehatan RI.Diakses September 2014. (www.depkes.go.id.infodatinpusatdatainform asikemenkesRI).

Lombo, Aprilia, dkk. 2015. Status karies anak usia prasekolah sekolah citra kasih yang mengonsumsi susu formula. Jurnal e-Gigi (eG), volume 3, nomor 1, Januari-Juni 2015. Manado: Program studi pendidikan dokter gigi fakultas kedokteran, universitas Sam Ratulangi Manado.

Machfoedz, Ircham. 2008. Menjaga kesehatan gigi dan mulut anak-anak dan ibu hamil. Yogyakarta: Fitramaya. 
Mariati, N.w. 2015. Pencegahan dan perawatan karies rampan.Jurnal Biomedik (JBM), Volume 7, Nomor 1, Maret 2015, hlm. 2328. Manado:Program studi pendidikan dokter gigi fakultas kedokteran, universitas Sam Ratulangi Manado.

Mumpuni, yekti. dan Erlita Pratiwi. (2013). 45 masalah dan solusi penyakit gigi dan mulut. Yogyakarta: Rapha publishing.

Neilson, Joan. (1987). Perawatan bayi, tahun pertama. Jakarta: Arcan.

Rahmawati (2016). Pengaruh penggunaan susu botol terhadap terjadinya rampan karies pada anak Tk Al Bahra Kampung beru desa Bululoe kabupaten Jeneponto. Makassar: Jurusan keperawatan gigi Poltekkes kemenkes Makassar.

Sadimin, dkk. 2017. Faktor-faktor penyebab rampan karies pada siswa TK Pertiwi Jembunngan 1 kabupatenBoyolali. Jurnal kesehatan gigi vol.04, no.1, Juni 2017. Semarang: Jurusan keperawatan gigi Poltekkes kemenkes Semarang-Indonesia.

Sari, EP. 2017. Hubungan pemberian susu formula dengan karies gigi pada anak pra sekolah di Tk Daniyyah Kids. Akademi kebidanan Dharma Husada Pekanbaru.

Sartika, dewi. (2012). Hubungan lamanya pemberian susu formula dengan tingkat keparahan karies gigi pada anakusia 2-6 tahun". Makassar: Fakultas kedokteran gigi Universitas Hasanuddin.

Setiaji, Bamandita Rahma. 2019. Apa bedanya rampan karies dengan rampan botol. Diakses $21 \quad$ Juni 2019. (https://hellosehat.com/hidup-sehat/gigimulut/beda-karies-rampan-dan-botol/).

Simkin, Penny. Dkk. (2007). Kehamilan, melahirkan, \& bayi: panduan lengkap. Jakarta: Arcan.

Srigupta, A.A. (2004). Panduan singkat Perawatan gigi dan mulut. Jakarta: Prestasi pustaka publisher.

Tarigan, Rasinta. (2013). Karies gigi.Jakarta:EGC

Winarno, F.G. (1990). Gizi dan makanan bagi bayi dan anak sapihan. Jakarta: Pustaka sinar harapan. 